\title{
Metallic additive manufacturing: state-of-the-art review and prospects
}

\author{
Benjamin Vayre ${ }^{\mathrm{a}}$, Frédéric Vignat ${ }^{\mathrm{b}}$ and François Villeneuve ${ }^{\mathrm{c}}$ \\ Grenoble-INP/UJF-Grenoble 1/CNRS, G-SCOP UMR 5272, 46 avenue Félix Viallet, 38031 Grenoble, France
}

Received 5 October 2011, Accepted 17 January 2012

\begin{abstract}
Additive manufacturing processes, used for more than 25 years, are no longer confined to rapid prototyping applications. Mostly used nowadays in niche markets (medical applications, aerospace...) to manufacture metallic parts, they should provide improvements in terms of time-to-market, ecological impact and design compared to traditional industrial processes. Current metallic additive manufacturing studied in this paper are Selective Laser Sintering, Direct Metal Laser Sintering, Selective Laser Melting, Electron Beam Melting and Direct Metal Deposition. The performances of these processes are investigated through criteria derived from the time cost quality triangle and some prospects concerning these processes are given.
\end{abstract}

Key words: Rapid manufacturing / additive manufacturing / laser sintering / laser melting / electron beam melting / direct metal deposition

Résumé - États des lieux des technologies de fabrication additive métallique. Les procédés de fabrication additifs, qui existent depuis près de 25 ans, ne sont plus aujourd'hui réservés au seul prototypage rapide. Aujourd'hui utilisés dans des marchés de niche (monde médical, aérospatial, ... ) pour fabriquer des pièces métalliques, ils laissent entrevoir d'importants gains en termes de temps de mise sur le marché, de réduction d'impact environnemental des produits manufacturés et de possibilités concernant la réalisation de formes complexes impossibles à réaliser actuellement. Les technologies de fabrication additive métallique étudiées dans cet article sont le frittage sélectif Laser (SLS), le frittage sélectif Laser direct (DMLS), la fusion sélective Laser (SLM), la fusion par faisceau d'électrons (EBM) et la construction Laser additive directe (DMD). Leurs performances sont analysées par rapport à des critères dérivés du triptyque industriel qualité-coût-délai. Enfin, nous concluons sur les actions à mener pour continuer à faire émerger ces procédés dans l'industrie.

Mots clés : Production rapide / fabrication additive / frittage Laser / fusion Laser / fusion par faisceau d'électrons / conception laser additive directe

\section{Introduction}

Traditional manufacturing technologies are based on multi-stage processes. The first stage deals with the rough part creation and the following stages usually consist in material removal operations. Creating a metallic rough part from raw material and later removing most of its volume can be found outdated. Moreover, each stage of the manufacturing process can take place in a different location hence generating transportation and thus energy

\footnotetext{
a Corresponding author:

benjamin.vayre@g-scop.inpg.fr

b Associate Professor

c Professor.
}

consumption. Additive manufacturing technologies can build fully functional parts in a single operation without wasting much raw material. These processes seem promising since they also could give the designers more freedom concerning the geometrical entities that can be manufactured.

Knowing how these manufacturing processes fare compared to conventional ones is a crucial question. Although this question is yet to be answered, in this paper the foundations needed to answer it will be laid out. At first, the different current additive manufacturing processes with their strong and weak spots will be presented. Then the characteristics of these processes in relation to the most important criteria to evaluate manufacturing processes 


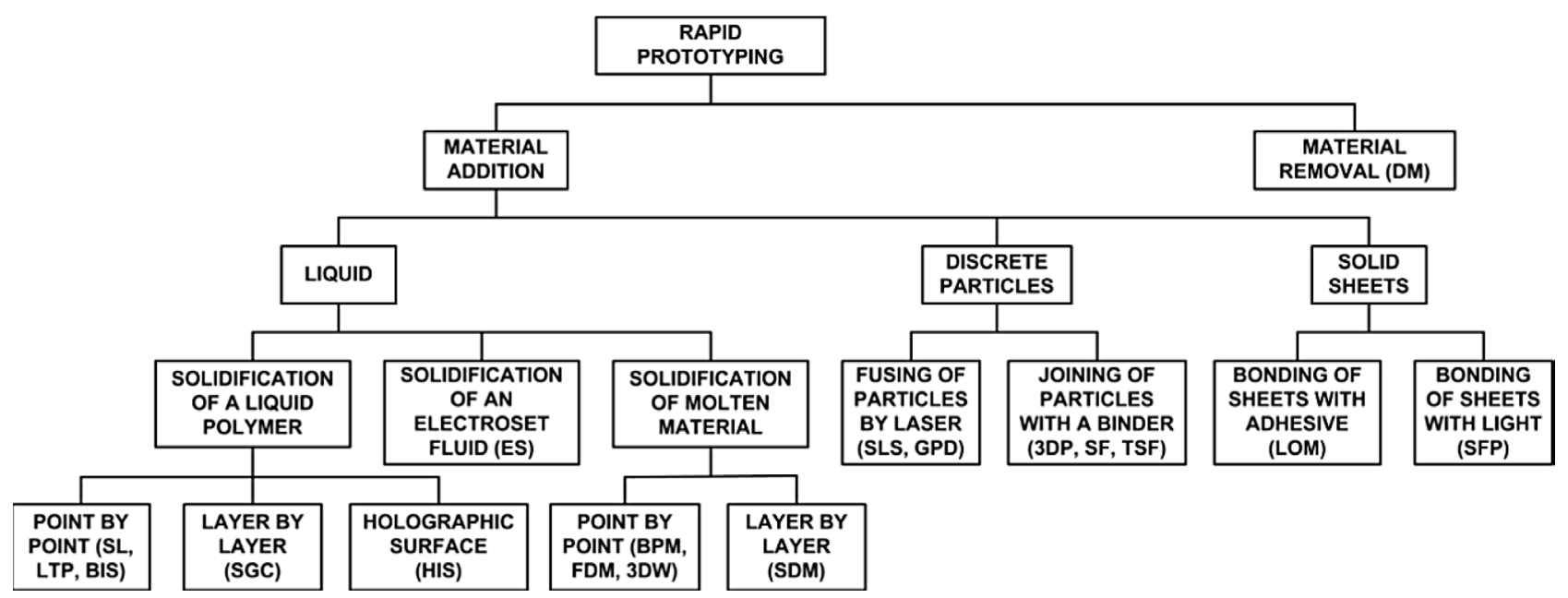

Fig. 1. Classification of different additive manufacturing technologies [2].

will be studied. To conclude, the results will be synthesized and some prospects on the future of these technologies and the conditions to their success will be proposed.

\section{Definition}

Additive manufacturing processes have existed for almost 25 years, i.e. stereolithography (SL), fused deposition material (FDM) and laminated object manufacturing (LOM) were invented in the late 1980's. Many other processes followed and were quickly adopted for rapid prototyping. The prototypes were built from polymer, wood or paper. With the diversification of additive processes together with the widening of available materials, it is now possible to directly manufacture metallic parts which meet the designer's specifications, in terms of shape (geometry), material and mechanical behavior. Rapid Prototyping is becoming Rapid Manufacturing.

Additive manufacturing can either be direct or indirect (Rapid Tooling). Direct additive manufacturing processes allow to manufacture end-use parts (or parts needing few post treatments) through deposition of either metallic alloy, plastic or ceramic material.

\section{Direct metallic additive manufacturing processes}

There are several ways to classify additive manufacturing processes. The first classification is made according to the type of material used to build up the part [1]. Another classification can be done according to the state of the raw material: liquid, discrete particle or solid sheet (Fig. 1).

For liquid and solid state raw materials the choice is limited to polymer (Stereolithography, Polyjet, and Fused Deposition Material), paper (Laminated Object Manufacturing) and wood (Stratoconception). Metallic raw materials for additive manufacturing only come under powder state. This paper will focus on direct metallic additive manufacturing and thus on the use of metallic powders. The processes presented in this paper are based either on layer or direct deposition.

\subsection{Layer-based metallic additive manufacturing}

Layer-based processes start from a 3D model of the part which is sliced into $20-150 \mu$ m-thick cross-sections. These sections are built one at a time, in an inert atmosphere or partial vacuum. An energy source (laser or electron beam) is used to scan each layer of powder to bind the material. After the section has been scanned, the piston of the building chamber is moved down and a roller deposits and presses down a new layer of powder. This process is repeated until the part is completed (Fig. 2). Once built, the part (or parts) is separated from the unbound powder and cleaned. The remaining powder is filtered and stored to be used for the upcoming fabrications.

These processes have specific constraints such as using supports. Their purpose is to prevent the collapse of molten (or sintered) metal inside the powder bed when manufacturing large overhanging surfaces, as well as dissipating the heat. The supports are generated during the pre-processing phase and made from the same material than the part (contrary to photopolymer based processes where different materials can be used). They are removed through mechanical operations upon completion of the part.

To improve the building rate of these processes, the building chamber is usually heated to minimize the quantity of energy to be brought at the focal point. The different layer based processes studied bind the particles via multiple mechanisms (Fig. 3). The particles are either fully melted (SLM, EBM, DMD) or partially melted (SLS, DMLS) using laser or electron beam as a source of energy. 

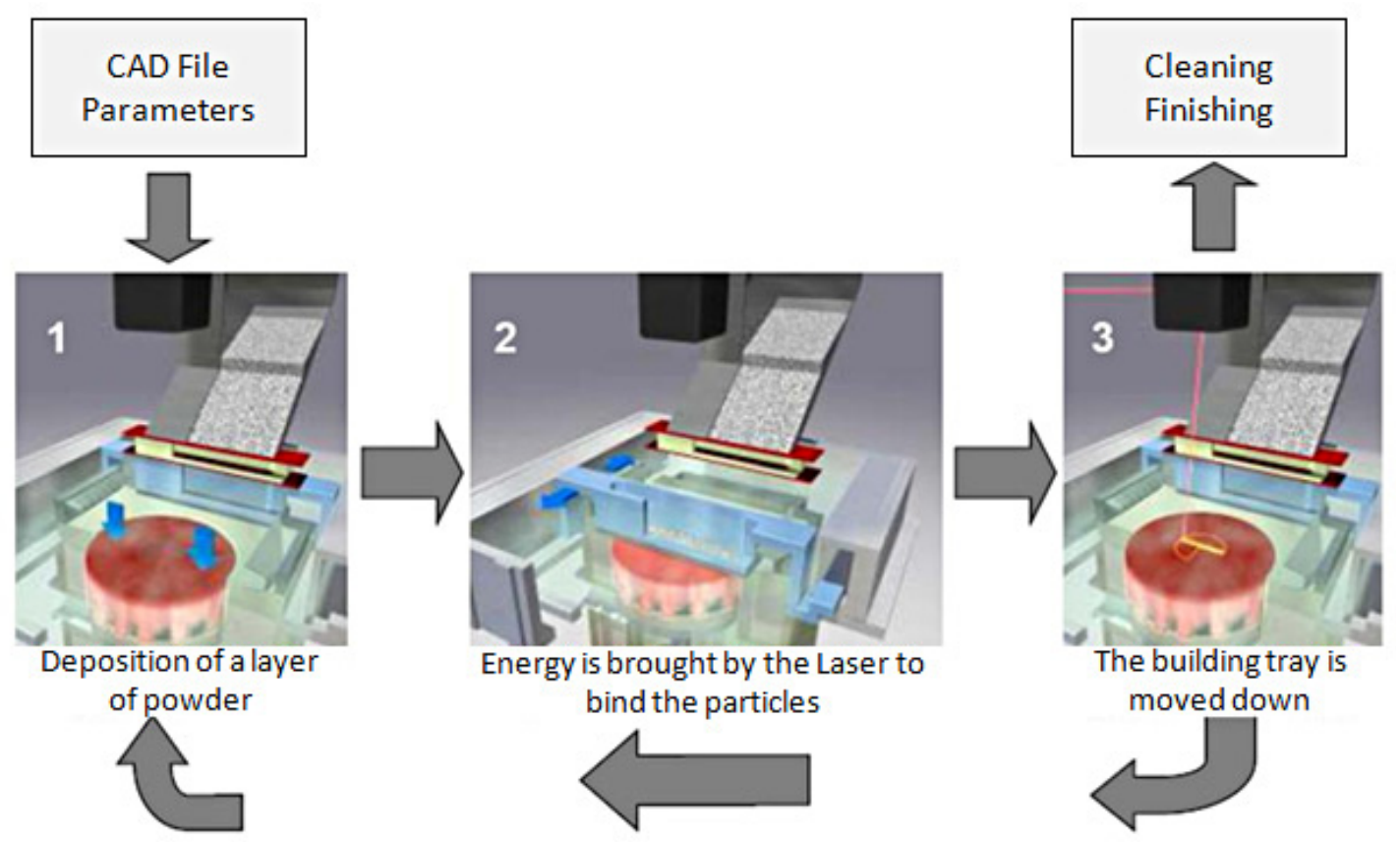

Fig. 2. Layer based fabrication's principle [Trumpf].

Binding mechanism classification

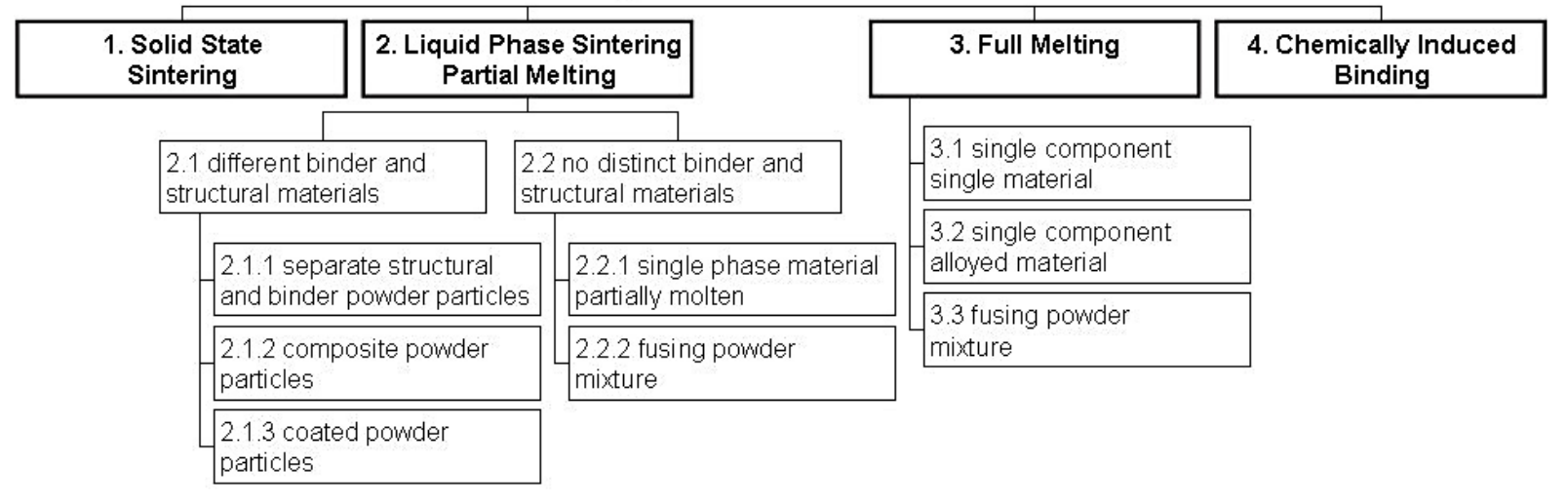

Fig. 3. Binding mechanism of additive manufacturing processes [3].

\subsubsection{Selective laser sintering}

The first powder-bed based process invented was SLS. It was patented by Ross Householder in 1979 and started to be sold in 1992 by DTM Corporation. Initially the only available material was polymer powder, either amorphous or semi-crystalline (case 2.2.1 in Fig. 3). Since the 1990 's, DTM widened the range of available materials by adding reinforced polymers (2.1.1 and 2.1.3), as well as using other materials coated with polymer.

These new materials include ceramics, used to produce casting molds and cores, and metallic alloys. After the fabrication is completed, the part is placed in an oven to vaporize the binding polymer, sinter the part and infiltrate it with a molten metal with a lower fusion temperature (such as bronze) to improve the mechanical behavior of the part and fill in porosities [4].
This process, mainly used for rapid prototyping but also for rapid manufacturing, has a high building speed [5] but a long curing phase.

\subsubsection{Direct metal laser sintering}

In the 90's, EOS developed a variant of SLS able to build metallic parts without using polymer to bind the particles (2.2.1 and 2.2.2 in Fig. 3) hence removing the curing phase. The energy brought by the Laser melts the peripheral region of the particle while its core remains solid. The molten metal acts as a binder, creating gates between the particles. The powder can include several metals, in that case, the metal with the lowest fusion temperature acts as the binder.

Due to the binding mechanism, the parts are porous with reasonable mechanical properties [5]. This 


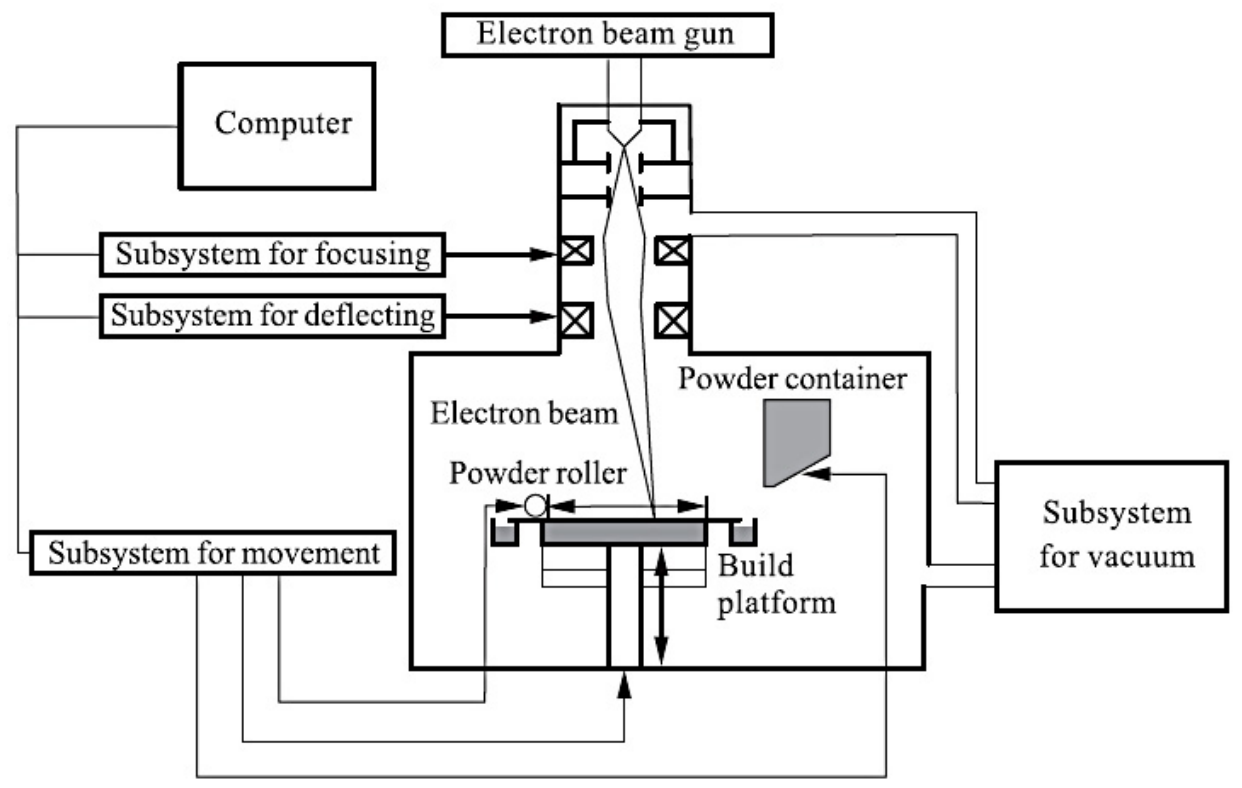

Fig. 4. EBM's principle [8].

characteristic proves useful to manufacture filters or gas storage systems for example. To obtain fully dense or gas proof parts, an infiltration is required.

\subsubsection{Selective laser melting}

SLM is based on the use of more powerful laser than both SLS and DMLS. The density of energy at the building spot is high enough to fully melt the powder. The parts manufactured have no or few porosities (if the gap between the scanning paths is small enough). The optimization of the parameters is crucial to obtain good surface quality $[6,7]$. Due to the higher temperature involved, shrinkage affects the parts, as well as thermal distorsion.

\subsubsection{Electron beam melting}

Electron Beam Melting was made commercial by Arcam in 1997. This process is similar to SLM with a difference on the nature of the energy source: an electron beam instead of a laser (Fig. 4). The lack of moving parts to guide the building spot makes high scanning speed possible (up to several kilometers per second). Moreover, the increase of the energy density at the building spot allows the use of a large variety of metallic alloys. These two factors explain the high building speed. This process also doesn't require any specific curing operation. Due to the large quantity of energy absorbed by the part, shrinkage takes place. The scanning strategy proves an important factor to minimize heat diffusion inside the powder bed and to improve the part's quality [8].

\subsection{Direct metal deposition}

Direct metal deposition consists in spraying the metallic powder directly onto a laser beam (usually a kilo-watt $\mathrm{CO}_{2}$ laser) (Fig. 5). The molten drops are then used to build the parts. Various metallic alloys are available and it is possible to gradually and continuously change from a material to another one while manufacturing. This particularity makes possible the manufacture of multimaterial parts. The nozzle is usually mounted onto a 5 axis CNC structure to produce complex parts. In that case, a pre-processing phase is required to generate the nozzle trajectories. This generation is complex due to its high influence on the final result.

Contrary to layer based processes where the thickness of each layer is constant, the thickness of the DMD joint depends on the speed of the nozzle and on the rate of material deposition. The rate of material deposition depends on multiple parameters: powder flow, Laser power, gas flow... Any difference between the manufactured and expected thickness can cause the failure of the construction since the distance between the nozzle and the surface can slowly grow, and that consequently the molten particles solidify before reaching the part. To prevent this phenomenon, an optical system can be used to monitor the distance between the nozzle and the part (Fig. 5).

Initially designed for remanufacturing or repair by material addition, this process can be used to manufacture end user parts with high added value.

\section{Evaluating the metallic additive manufacturing processes}

Numerous papers focus on designing test parts and evaluating metallic additive manufacturing processes [5, $9,10]$. Due to the large variety of processes, these studies 


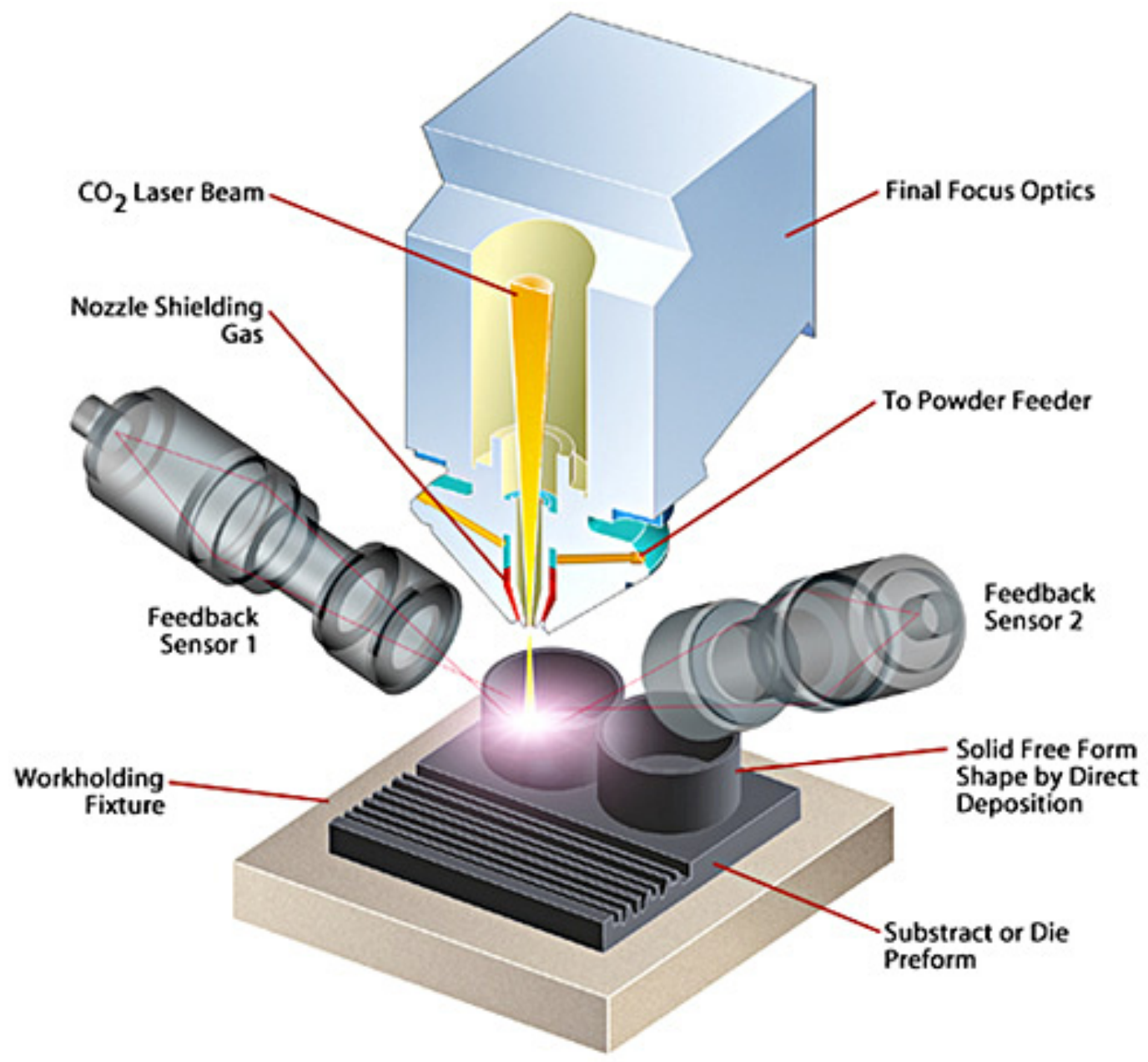

Fig. 5. DMD's principle $[\mathrm{POM}]$.

prove difficult to use and show partial results. The main criteria used to evaluate a process can be derived from the time - cost - quality triangle. This triangle can today become a square by addition of the environmental impact. In this paper the proposed manufacturing processes will be compared regarding these 4 criteria.

\subsection{Quality}

\subsubsection{Surface quality}

Parts manufactured with this kind of processes generally have a granular aspect due to the binding of unmolten particles on the exterior of the parts. The arithmetic rugosity of the surfaces is below $15 \mu \mathrm{m}$ for the powder bed based processes. The surfaces build with SLS (and with DMLS + infiltration) have a better quality than the ones made through SLM and uninfiltered DMLS, thanks to the infiltration which smoothens the surfaces [5]. The arithmetic rugosity of EBM made parts is usually between 25 and $35 \mu \mathrm{m}$ (according to Arcam) whereas DMD produces smoother surfaces with $R a$ between 10 and $25 \mu \mathrm{m}$ (according to POM).

\subsubsection{Dimensionnal quality}

SLS, DMLS and SLM processes produce parts with dimensional errors of less than $0.1 \mathrm{~mm}$ for a $100 \mathrm{~mm}$ length (3D system). EBM dimensional precision is half as good whereas DMD's is three times worse (POM). This is just an estimate since smaller additive manufacturing machines exist for several processes (for instance, Easyclad sells two DMD nozzles: Macro-Clad for large parts and Meso-Clad for small ones) which produce parts with better dimensional and surface quality. On a general note, when good surface or dimensional quality is needed, finishing operations are necessary.

\subsubsection{Materials and mechanical properties}

RM has been widening the range of available material since its invention. Nowadays, it's possible to build parts with CNC like material [13] and some processes can manufacture multi-material parts [14]. The increase in power of the Laser sources used in SLS, DMLS and SLM allow the use of high melting point metallic alloys. The mechanical properties of the sintered and molten material tend to be similar or even better than the machined one, the microstructure being more and more controlled $[15,16]$. 


\subsection{Time}

Few studies focus on the manufacturing speed of different RM processes since it's difficult to build a part under the same conditions on different manufacturing processes. The data below are given by the manufacturers for machines able to build "medium sized" parts (the building volume has dimensions of at least $200 \mathrm{~mm} \times 200 \mathrm{~mm}$ $\times 200 \mathrm{~mm})$.

Additive manufacturing processes based on sintering, SLS $\left(10-100 \mathrm{~cm}^{3} / \mathrm{h}\right)$ and DMLS $\left(7-70 \mathrm{~cm}^{3} / \mathrm{h}\right)$ are fairly faster than SLM $\left(5-20 \mathrm{~cm}^{3} / \mathrm{h}\right)$. DMD $\left(10-70 \mathrm{~cm}^{3} / \mathrm{h}\right)$ and EBM $\left(55-80 \mathrm{~cm}^{3} / \mathrm{h}\right)$ are able to produce non-porous parts, as SLM does, with a higher building speed. This data is usually measured with maximum layer thickness (except for DMD, not layer-based). When producing parts, to minimize stair effect [11] on complex parts, hence limiting the finishing operations, smaller layer thickness should be chosen. Real building speed will then often be closer to the lower given value and can even be lower since the speed also depends on the material used.

SLS and DMLS processes, though having similar building speed than EBM and DMD processes, require an infiltration to obtain nearly fully dense parts [4]. The fastest processes to manufacture parts without specific finishing operations are EBM and DMD processes.

EBM allows the user to change the diameter of the building spot diameter from $200 \mu \mathrm{m}$ to $1 \mathrm{~mm}$. With this process, it's possible to build small entities as well as fill in quickly large volumes (compared to SLM for example where the focal spot has a fixed diameter of $70 \mu \mathrm{m}$ ). To have the same flexibility on laser based processes, machines with multiple laser are experimented to have multiple scanning spot at the same time [12].

\subsection{Cost}

Manufacturing cost depends on machine operating cost, raw material and consumables costs, manufacturing time... with all the parameters varying based on the use and type of the machine. On a general level, for a medium building chamber volume, sintering-based processes are the least expensive whereas EBM and DMD are the most expensive. The high price of these machines is balanced by the very short pre-production phase for small series. The price of metallic powders is greatly impacted by the atomization process which reduces the price difference between different alloys.

\subsection{Environmental impact}

About 95 per cent (according to Arcam) of the unused powder can be filtered and used again right away. Moreover the ability to manufacture less massive parts and/or closer to the designer's wishes is very interesting for ecodesigners [17]. The environmental impact of several SLS and SLM machines manufacturing a test part was quantified [18] and shows that the fabrication impact can't be

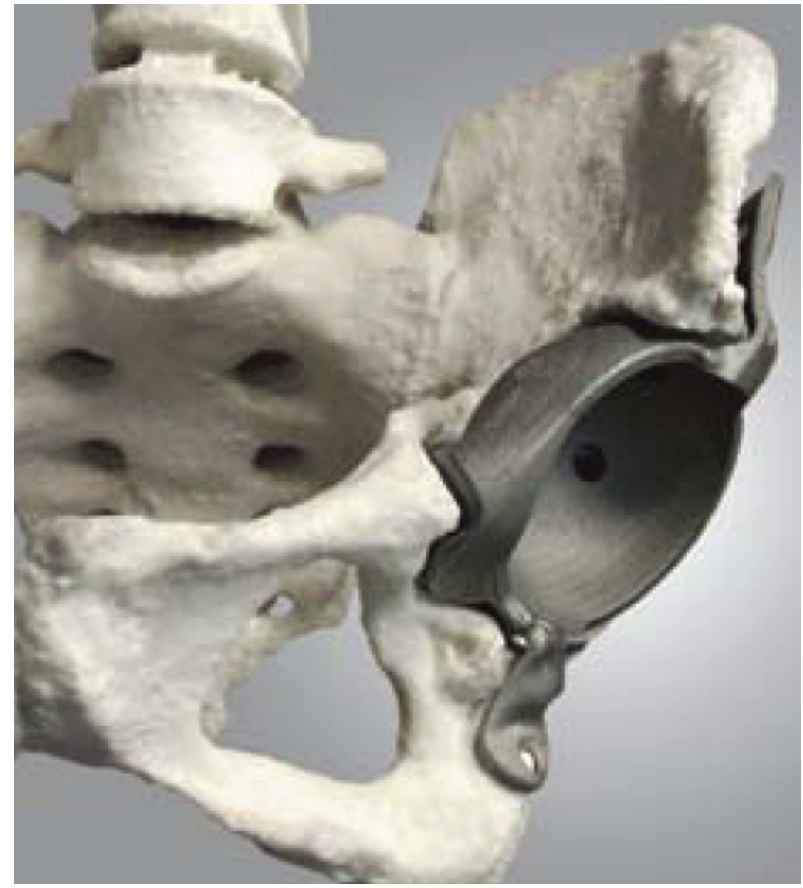

Fig. 6. Hip replacement manufactured by SLM.

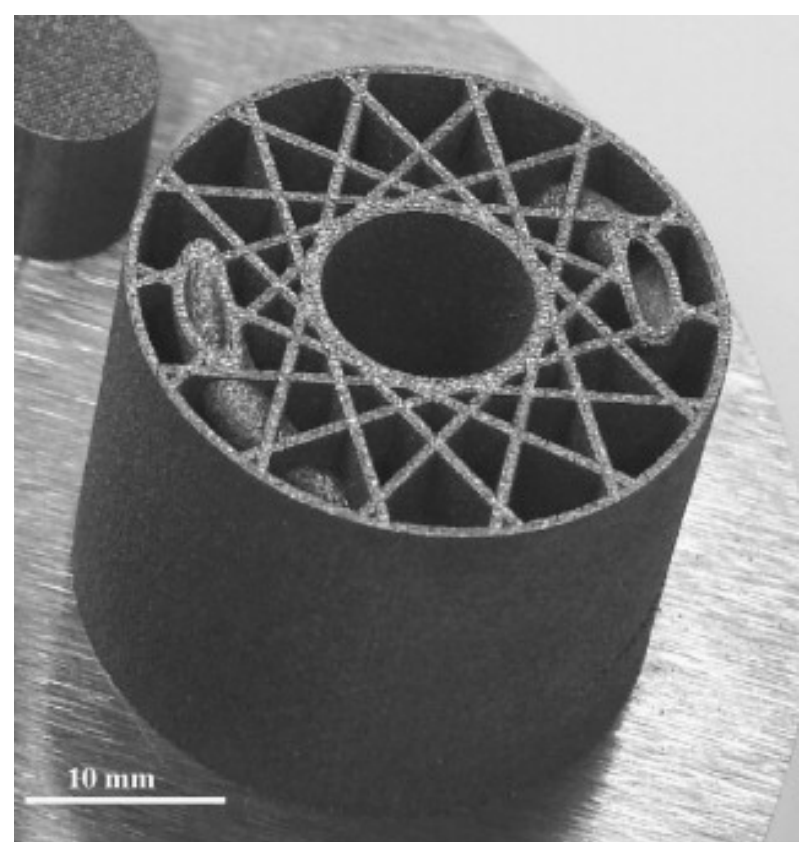

Fig. 7. Example of optimized inner structure built with SLM [19].

disregarded compared to extraction and creation phases. It would be interesting to compare these performances to those of traditional mechanical processes. Newly-built parts only need the cleaning of the remaining powder (contrary to stereolithography where solvents are used) which contributes to the limitation of waste generation. To obtain good surface quality, finishing operations are usually needed. 


\subsection{Synthesis}

\begin{tabular}{|c|c|c|c|c|c|}
\hline Technology & SLS & DMLS & SLM & EBM & DMD \\
\hline Manufacturer & $\begin{array}{l}\text { 3D system - } \\
\text { DTM Corp. }\end{array}$ & EOS GmbH & $\begin{array}{l}\text { 3D system - } \\
\text { MTT }\end{array}$ & Arcam & $\begin{array}{l}\text { POM - } \\
\text { Easyclad }\end{array}$ \\
\hline $\begin{array}{l}\text { Maximal building volume* } \\
\left(\text { in } \mathrm{mm}^{3}\right)\end{array}$ & $550 \times 550 \times 750$ & $250 \times 250 \times 215$ & $400 \times 400 \times 400$ & $200 \times 200 \times 350$ & $300 \times 300 \times 300$ \\
\hline Building speed* (in $\mathrm{cm}^{3} / \mathrm{h}$ ) & $10-100$ & $7-70$ & $5-20$ & $55-80$ & $10-70$ \\
\hline Post-process operations & $\begin{array}{c}\text { Cleaning } \\
\text { (infiltration) } \\
\text { (finishing) }\end{array}$ & $\begin{array}{c}\text { Cleaning } \\
\text { (infiltration) } \\
\text { (finishing) }\end{array}$ & $\begin{array}{l}\text { Cleaning } \\
\text { (finishing) }\end{array}$ & $\begin{array}{l}\text { Cleaning } \\
\text { (finishing) }\end{array}$ & (finishing) \\
\hline Layer thickness* & $20-150 \mu \mathrm{m}$ & $20-100 \mu \mathrm{m}$ & $20-100 \mu \mathrm{m}$ & $50-200 \mu \mathrm{m}$ & - \\
\hline Rugosity (in $\mu \mathrm{m}$ ) & $\operatorname{Ra} 2[5]$ & $\operatorname{Ra} 11[5]$ & $\operatorname{Ra} 11[5]$ & Ra $25-35^{*}$ & Ra $10-25^{*}$ \\
\hline Dimensional quality* & $0.2^{*} \mathrm{~mm}$ & $0.1-0.2^{*} \mathrm{~mm}$ & $0.2^{*} \mathrm{~mm}$ & $0.4^{*} \mathrm{~mm}$ & $0.3^{*} \mathrm{~mm}$ \\
\hline $\begin{array}{l}\text { Available metallic } \\
\text { materials* }\end{array}$ & $\begin{array}{l}\text { Any coated } \\
\text { material }\end{array}$ & $\begin{array}{c}\text { Steels, } \\
\text { cobalt-chrome, } \\
\text { aluminum, } \\
\text { bronze, } \\
\text { titanium. }\end{array}$ & $\begin{array}{c}\text { Steels, } \\
\text { cobalt-chrome, } \\
\text { aluminum, } \\
\text { bronze, } \\
\text { titanium. }\end{array}$ & $\begin{array}{c}\text { Steels, } \\
\text { cobalt-chrome, } \\
\text { aluminum, } \\
\text { bronze, } \\
\text { titanium, } \\
\text { inconel, } \\
\text { copper, } \\
\text { beryllium, } \\
\text { niobium, ... }\end{array}$ & $\begin{array}{c}\text { Steels, } \\
\text { inconel, copper, } \\
\text { titanium,... }\end{array}$ \\
\hline
\end{tabular}

* Manufacturer data (3D system, EOS GmbH, Arcam, POM).

\section{Conclusion}

Metallic additive manufacturing is already used to produce unique or small series of complex parts, particularly to build medical prosthesis (Fig. 6).

To continue spreading in the mechanical industries, rapid manufacturing processes should continue to improve their performances in terms of speed, precision and exploitation costs. Using these processes should now be considered from the early designing phases to take advantage of the freedom of the buildable shapes which can lead to building less massive or more functional parts (Fig. 7). Current CAD tools and, more generally, the numerical chain should change to take into account the new features of rapid manufacturing built parts: multimaterial parts, inner structures, colored surfaces (with 3D printing for instance), etc. [20]. In addition, the question of the environmental impact of these manufacturing technologies is still unanswered. It should be investigated through several case studies assess their strengths.

\section{References}

[1] G.N. Levy, R. Schindel, J. Kruth, Rapid prototyping and manufacturing technology: principle, representative technics, applications, and development trends, CIRP Annals - Manuf. Technol. 52 (2003) 589-609

[2] D. Pham, R. Gault, A comparison of rapid prototyping technologies, Int. J. Machine Tools Manuf. 38 (1998) $1257-1287$

[3] J. Kruth, G. Levy, F. Klocke, T. Childs, Consolidation phenomena in laser and powder-bed based layered manufacturing, CIRP Annals - Manuf. Technol. 56 (2007) 730-759
[4] S. Kumar, J. Kruth, Effect of bronze infiltration into laser sintered metallic parts, Materials \& Design 28 (2007) 400-407

[5] P.J. Kruth, B. Vandenbroucke, I.J. van Vaerenbergh, P. Mercelis, Benchmarking of different SLS/SLM processes as rapid manufacturing techniques, 2005

[6] I. Yadroitsev, A. Gusarov, I. Yadroitsava, I. Smurov, Single track formation in selective laser melting of metal powders, J. Mater. Proc. Technol. 210 (2010) 1624-1631

[7] I. Yadroitsev, P. Bertrand, I. Smurov, Parametric analysis of the selective laser melting process, Appl. Surf. Sci. 253 (2007) 8064-8069

[8] W. Lu, F. Lin, J. Han, H. Qi, N. Yan, Scan strategy in electron beam selective melting, Tsinghua Science \& Technology 14 (2009) 120-126

[9] F. Xu, Y.S. Wong, H.T. Loh, Toward generic models for comparative evaluation and process selection in rapid prototyping and manufacturing, J. Manuf. Sys. 19 (2001) 283-296

[10] D. Scaravetti, P. Dubois, R. Duchamp, Qualification of rapid prototyping tools: proposition of a procedure and a test part, Int. J. Adv. Manuf. Technol. 38 (2007) 683-690

[11] D. Ahn, H. Kim, S. Lee, Surface roughness prediction using measured data and interpolation in layered manufacturing, J. Mater. Proc. Technol. 209 (2009) 664-671

[12] H. Kim, K. Choi, Y. Doh, D. Kim, Fabrication of parts and their evaluation using a dual laser in the solid freeform fabrication system, J. Mater. Proc. Technol. 209 (2009) 4857-4866

[13] J. Kruth, L. Froyen, M. Rombouts, J. Van Vaerenbergh, P. Mercells, New ferro powder for selective laser sintering of dense parts, CIRP Annals - Manufacturing Technology 52 (2003) 139-142 
[14] A. Yakovlev, E. Trunova, D. Grevey, M. Pilloz, I. Smurov, Laser-assisted direct manufacturing of functionally graded 3D objects, Surface and Coatings Technology 190 (2005) 15-24

[15] L. Murr et al., Microstructures and mechanical properties of electron beam-rapid manufactured Ti-6Al-4V biomedical prototypes compared to wrought Ti-6Al-4V, Materials Characterization 60 (2009) 96-105

[16] S. Biamino et al., Electron beam melting of Ti-48Al-2Cr$2 \mathrm{Nb}$ alloy: Microstructure and mechanical properties investigation, Intermetallics

[17] O. Diegel, S. Singamneni, S. Reay, A. Withell, Tools for Sustainable product design: additive manufacturing, J. Sustainable Development 3 (2010) 68-75
[18] K. Kellens, W. Dewulf, E. Yasa, J. Duflou, Environmental analysis of SLM and SLS manufacturing processes, Proceeding of the 17th CIRP International Conference on Life Cycle Engineering, 17 location: Hefei, China date: 2010, pp. 423-428

[19] I. Yadroitsev, L. Thivillon, P. Bertrand, I. Smurov, Strategy of manufacturing components with designed internal structure by selective laser melting of metallic powder, Appl. Surf. Sci. 254 (2007) 980-983

[20] R. Bonnard, P. Mognol, J. Hascoët, A new digital chain for additive manufacturing processes, Virt. Phys. Prototyp. 5 (2010) 75 